\title{
Study on the National Supply-side Structural Reform Based on Improving the Quality of Petroleum and Petrochemical Equipment
}

\author{
Zhuohang Lv \\ China Petroleum Technology Development Co., Ltd., China.
}

\begin{abstract}
Improving quality is the foundation of promoting national strength, as well as the foundation of establishment and enterprise transformation. In the13th five-year plan period in China, China's petrochemical industry pay attention to improve the service level and create more social value, vigorously improve the overall quality and efficiency of supply, become more and more professional in procurement, make positive use of Internet and computer technology, build the industrial electric business platform, provides the material supply and marketing of more convenient and quick way, speed up the transformation and upgrading of service, and provide great power for improving the quality of petroleum and petrochemical equipment.
\end{abstract}

Keywords: petroleum and petrochemical; quality; reform.

\section{Introduction}

The 13th five-year plan provides guidance for the development of China, and also provides certain opportunities for the transformation and development of petrochemical enterprises in China. Sinopec will fully implement the party's strategic layout, actively reform the innovation, take the development of the green, harmony and sharing as the main idea, actively use of the Internet and computer technology, to create industrial electric business platform, take the improvement of the quality of service quality and efficiency of the supply system as the main development direction, promote transformation and upgrading of procurement mode and type of service, so as to better improve the quality of petroleum and petrochemical equipment, provide the power for the transformation and upgrading of Chinese products, better practice the supply side reform strategy of China.

\section{Concept of Safe Development}

Improving the quality of products can enhance China's competitiveness in the international market and provide a basis for the transformation and upgrading of China's industries and products. Petroleum and petrochemical enterprises pay attention to scale and continuous production. Generally, large equipment is applied in enterprises and the industrial chain is relatively complete. Due to the increase of demand, the operation time of the equipment is very long in the production process, which leads to the accelerated aging of many equipment which are easy to be damaged and corroded under the condition of high temperature and high pressure and in this situation the safety accidents are very prone to happen. During the 13th five-year plan period, the state pays attention to the quality of products, took safe production and safe supply as the main development concept, strengthened supervision and management from various links to ensure safety. It provides certain guarantee for the safe and stable operation of petrochemical equipment and makes petrochemical products more and more green and safe. Security development can start from the following aspects.

1. Ensure safe supply. In the process of procurement, safety must be taken as the first index. When safety procurement conflicts with supply and cost requirements, safety must be put in the first place and quality defective products should be avoided to the greatest extent to ensure the final production quality and avoid safety accidents.

2.Seek better prices and lower costs. In the procurement of materials, low price and high performance is needed to reduce the cost of input. We can not only blindly focus on quality and performance and excessive cost increase, also cannot blindly reduce costs and select quality unqualified products. Scientific and reasonable procurement should not only plan the price of the product, but also take the product's performance into account, service life and maintenance difficulty 
after damage, maintenance cost and environmental protection degree. All factors should be considered to select the most appropriate products to complete procurement tasks.

3. Green procurement. At present, China attaches great importance to environmental protection, more and more people begin to practice the green lifestyle and production mode. In the procurement of materials, the green procurement is also needed as the main idea. When buying, the environmental protection performance of the product should take into consideration, not only to meet the quality requirement of production, but also to save energy, reduce pollution, and to realize the harmonious green healthy development of person and natural environment.

\section{Establish and Improve the Related Standards and Regulations.}

The development of modern industry is inseparable from the formulation and restriction of standards. Of China's 2011-2020 "quality development compendium" the standardization is included in the development of quality planning, the compendium stipulate that it should make full advantage of the enterprise's leadership, implement the central enterprises and advantages in accordance with international standards, take the national standards and industry standards in practical application to the actual production, better improve the quality and level of the production. In April 2012, Sinopec formally launched the plan of standardized procurement, standardized design and modular construction, and formulated the relatively perfect procurement process and procurement technical standards, which provided better guarantee and system specification for procurement work, and was conducive to the establishment and improvement of the standard procurement system. During the 13th five-year plan period, Sinopec actively reformed itself and made continuous efforts to establish a standardized procurement system.

1. Improve procurement technology. Sinopec takes green, economic, reliable and practical as the main principle, take unified purchase and improve the technology as the main task, take the improvement of the scope of material and interoperability as the main target, carry on strict establishment to the petrochemical key material standard, take efforts to improve the level of specialization and standardization, provide the basis the standardization system establishment for procurement. Through continuous innovation and exploration, Sinopec has made strict supervision and management on the formulation and implementation of technical standards for procurement, thus accelerating the improvement of procurement quality. At the end of the 13th five-year plan, a relatively complete technical standard system for procurement has been initially formed.

2. Accelerate the research and development of domestic equipment. At present, a lot of equipment applied in China is imported from abroad. In recent years, the development goal of the country is also to make great efforts in innovation and reform to speed up the pace of localization of equipment. Therefore, we must adhere to the concept of innovation, actively and reasonably draw on the advanced technology and design concept of foreign countries, and actively make use of Internet technology and big database, in an effort to eliminate obstacles to materials, equipment and cost. Sinopec attaches great importance to the development of complete sets of equipment for oil and gas field development as well as specialized equipment required by coal chemical projects, which gives full play to the role of national advantageous enterprises, improves the research and development level of domestic equipment, and promotes the development process of Chinese manufacturing.

\section{Pay Attention to Quality and Honesty.}

Quality is the decisive factor of competition among enterprises. The success of enterprises must guarantee the quality of products. Adhering to the national development strategy and requirements, Sinopec has established justice, equity and honest supply management system, and a relatively perfect credit reward and punishment system, providing institutional guarantee for improving the quality of product supply.

1. Reduce the risks of suppliers from the source. Actively opening the door for suppliers can make the supply and circulation of products more convenient and efficient, and can also attract more 
excellent suppliers to participate in the procurement process. For supplier qualification and the quality of products strict comprehensive review is very important, to the quality and after-sales service and the management and social services and so on, which is to choose a better supplier, at the time of review to ensure that can meet the production process, product and management at the scene of the system, reduce the risk of suppliers from the source, ensure the supply smoothly.

2. Improve the credit system and conduct regular assessment on suppliers. Sinopec needs to assess suppliers regularly, publish the results regularly and criticize unqualified suppliers. We should establish a credit system and publicize the dissatisfactory behaviors of suppliers so as to better purify the market environment, pay attention to brand building and ensure the stability and smoothness of the supply system. Strive to create an open and transparent supply system.

IV. Strengthen quality management. In order to better realize the quality management, first of all, the quality of supplies should be guaranteed. The supplies should be strictly inspected by professionals, relevant standards should be formulated, and the personnel should be trained regularly to ensure the professional level of testing. In addition, the supervision of materials should be strengthened to ensure the quality of imported materials. In addition, quality inspection shall be carried out strictly, and the procedures and standards for inspection shall be standardized, and quality supervision shall be conducted from the aspects of supervision, on-site supervision, inspection and acceptance of goods, etc. so as to ensure quality conformity. A clear contract must be made to control the quality of the products. For the inspection and acceptance of the goods, the qualified rate of the stored products must be above $98 \%$.

\section{Establish High-quality E-commerce Platform.}

China's social development is speeding up, and the progress of science and technology also promotes the development of China's industry. Many industries actively make use of the Internet and computer technology to innovate and reform themselves, so that enterprises can better adapt to the needs of the modern market. As a large energy company, Sinopec established an e-commerce platform in 2015 and put it into use in June of the following year in order to reflect its management advantages and the trend of development in the trend of The Times, providing more professional and rapid services. The establishment of e-commerce platform has promoted the process of procurement specialization. With the concept of openness and sharing, it has better met the needs of the society and created more value for the society. In addition, it has also actively established cross-border ecommerce services, promoted the products made in China to go abroad, let more countries know about Chinese products, and promoted the process of Chinese creation and the establishment of Chinese brands.

\section{Conclusion}

The 13th five-year plan provides great development opportunities for the upgrading of China's petroleum and petrochemical industry. China petroleum and chemical industry will continue to innovate and develop in the inheritance, to improve their ability and level continuous, to speed up the procurement of materials innovation with constantly struggle, take efforts to create a higher quality, higher efficiency of the procurement chain to better combined with the Internet, the traditional industry to promote the innovation and development of traditional industries and traditional industries better into the modern development market, to inject more vigor to the development of traditional industries. We will actively develop industrial e-commerce platforms, better and faster strengthen the reform and development of the supply system, promote the overall improvement of the efficiency and quality of the supply system, and contribute to the country's supply-side reform. 


\section{References}

[1]. Lv Kun. Inheriting the innovation quality concept and improving the scientific and technological innovation ability to build an oil equipment base [J]. Excellent performance,2010(6).

[2]. Gao Jiasuo, Wang Guosheng. Application of modern testing technology in petroleum equipment [J]. Petroleum field machinery,2007(9).

[3]. Liu Xuemei, Shen Shuguo, Zhang bin. International standardization to promote the quality of petroleum equipment products [J]. Drilling technology,2008(6). 